\title{
Inattention/Hyperactivity Composite Score
}

National Cancer Institute

\section{Source}

National Cancer Institute. Inattention/Hyperactivity Composite Score. NCI Thesaurus.

Code C126881.

A composite score of the Behavior Assessment System for Children that combines the Attention Problems scale and the Hyperactivity scale. 